\title{
TECNOLOGIAS DIGITAIS DE INFORMAÇÃO E COMUNICAÇÃO NO ENSINO DA LÍNGUA PORTUGUESA
}

\section{DIGITAL INFORMATION AND COMMUNICATION TECHNOLOGIES IN PORTUGUESE LANGUAGE TEACHING}

\author{
Recebido: 30/10/2020 Aprovado: 06/12/2020 Publicado: 10/01/2021 \\ DOI: $10.18817 /$ rlj.v4i02.2395
}

\author{
Ricardo Santos David 1 \\ Orcid ID:http://orcid.org/0000-0001-5850-0057
}

\begin{abstract}
Resumo: O contexto social atual de pandemia e distanciamento social provocado pela COVID-19 (SARS-CoV-2), expôs a necessidade de intensificar o trabalho pedagógico de leitura com a utilização de diferentes recursos tecnológicos e o auxílio das Tecnologias Digitais de Informação e Comunicação. Este artigo tem como objetivo geral compreender o modo como às ferramentas de Tecnologias Digitais de Informação e Comunicação (TDIC) podem contribuir para os processos de ensino e de aprendizagem da Língua Portuguesa de alunos inseridos no $09^{\circ}$ ano do Ensino Fundamental. O uso das metodologias digitais é fundamental para que os alunos tenham acesso ao ensino em um período onde encontram-se impedidos de frequentar as escolas de maneira presencial. A análise realizada no sistema Aula Paraná evidenciou a inserção e o uso de tecnologias para o ensino da literatura. Espera-se que este artigo auxilie os professores na inserção destes espaços digitais motivando-os ao ensino dos diferentes gêneros da literatura com o auxílio de metodologias tecnológicas.
\end{abstract}

Palavras-chave: Ensino Língua Portuguesa. Tecnologia no Ensino e Aprendizagem. Leitura.

Abstract: The current social context of pandemic and social distance caused by COVID-19 (SARSCoV-2), exposed the need to intensify the pedagogical work of reading with the use of different technological resources and the aid of Digital Technologies of Information and Communication. This article has the general objective of understanding how the tools of Digital Technologies of Information and Communication (TDIC) can contribute to the processes of teaching and learning the Portuguese Language of students in the 9th grade of Elementary School. The use of digital methodologies is essential for students to have access to education in a period when they are prevented from attending schools in person. The analysis performed in the Aula Paraná system showed the insertion and use of technologies for teaching literature. It is hoped that this article will assist teachers in the insertion of these digital spaces, motivating them to teach different genres of literature with the help of technological methodologies.

Keywords: Portuguese Language Teaching. Technology in Teaching Learning. Reading.

\section{Introdução}

As aspirações humanas foram, ao longo dos anos, associadas à busca por melhorias, inovações constantes, praticidade e bem-estar no contexto de vida cotidiana, direcionaram os seres humanos, ao longo da história, à dedicação e ao investimento físico e financeiro em novos projetos de criações, invenções e

\footnotetext{
1 Pós-Doutorado em Educação: Formação de Professores e Novas Tecnologias, pelo IESLA FCU/EUA. Doutorado e Mestrado em Educação: Formação de Professores e Novas Tecnologias, pela UNIATLÁNTICO. Especialista em Docência do Ensino Superior, Linguística Aplicada e Literatura, pela UCAM/RJ. Graduação em Letras e Pedagogia. E-mail: ricardosdavid28@gmail.com
} 
reinvenções.

Como resultados, obtiveram-se a identificação de soluções de problemas, a transformação de diferentes processos e o surgimento de novos e modernos produtos (VÁSQUEZ, 1968). Sobre este último aspecto, o mesmo autor aponta que todo e qualquer instrumento criado ou modificado pelo homem, para facilitar o trabalho por ele desenvolvido, é classificado como tecnologia.

Juntamente com as modificações sociais decorrentes da inserção das tecnologias nos mais diferentes contextos e espaços, observa-se o surgimento da cibercultura, isto é, uma cultura contemporânea promovida pelos novos ciber avanços, intimamente ligados às tecnologias digitais. Entre as áreas da cibercultura que recebem destaque nos ciberespaços (LÉVY, 1999) aponta a comunicação e a informação com rapidez, constituídas principalmente pela ausência de necessidade física do homem na instituição de diálogos comunicacionais e relacionamentos.

Nos últimos anos as tecnologias têm se inserido, também, nos espaços escolares e se destacado como relevantes ferramentas no processo de organização e aplicação metodológica representadas pelas Tecnologias Digitais de Informação e Comunicação (TDIC). Em razão disso, os autores afirmam que os profissionais envolvidos na educação, devem fazer uso das tecnologias a fim de proporcionar aos alunos uma amplitude no processo de aprendizagem, por meio do estabelecimento de conexões entre as informações e a diversidade dos conteúdos trabalhados e aprendidos em sala de aula (LÉVY, 1999; CRUZ, 2008).

Embora esteja claro que a ciência, a tecnologia e a sociedade se correlacionam em um formato de tríade a fim de garantir a qualidade do ensino e da aprendizagem dos alunos de forma crítica e reflexiva compatível ao cotidiano e às necessidades tecnológicas do século XXI, observa-se que o incentivo e a promoção do interesse e da motivação dos alunos pela leitura dentro e fora das salas de aula, associado ao desenvolvimento de habilidades para a análise e a compreensão dos diferentes textos, ainda é um desafio enfrentado por educadores da Língua Portuguesa (PINHEIRO, 2007).

Verifica-se que a educação exige reestruturação, abandonando a forma tradicional de aprendizagem e adotando novas técnicas e ferramentas para que o processo de ensino e aprendizagem seja alcançado, a partir do desenvolvimento de estratégias que possibilitem a ampliação de competências e de habilidades para a produção, a compreensão e a interpretação linguístico-textual, levando em 
consideração a diversidade do alunado em suas formas de compreensão e, atendendo a demanda desta nova geração que emerge na utilização das TDIC, oferecendo aos alunos ferramentas para motivação e aproximação do educando a leitura. Neste contexto, o papel do professor é fundamental, pois é considerado um "incentivador que torna-se um animador da inteligência coletiva de seus grupos de alunos, em vez de fornecedor direto de conhecimentos" (LÉVY, 1999, p. 158).

O contexto social atual de pandemia, provocado pela COVID-19 (SARSCoV-2), expôs a necessidade de intensificar o trabalho pedagógico de leitura e com a utilização de diferentes recursos tecnológicos. Devido à suspensão das aulas presenciais em todo o território brasileiro no mês de Março de 2020, a solução encontrada para a continuidade ao processo de ensino de milhares de estudantes da rede estadual no Estado do Paraná, foram às aulas a distância por meio do ensino remoto, com o auxílio das TDIC.

Considerando os cenários tecnológicos e contextos sociais acima destacados, surge a seguinte questão que move a pesquisa: "Como as TDIC podem auxiliar e maximizar o processo de ensino, aprendizagem e incentivo ao desenvolvimento das habilidades de leitura de alunos do $09^{\circ}$ ano do Ensino Fundamental e quais estratégias têm sido empregadas no cenário atual?"

Para responder às questões acima destacadas o presente artigo tem como objetivo geral compreender o modo como às ferramentas de Tecnologias Digitais de Informação e Comunicação (TDIC) podem contribuir para os processos de ensino e de aprendizagem da Língua Portuguesa de alunos inseridos no $09^{\circ}$ ano do Ensino Fundamental. Os objetivos específicos do estudo são: (1) Verificar como a leitura é concebida na Base Nacional Comum Curricular (BNCC) e discutir a leitura em relação aos multiletramentos e às TDIC; (2) Compreender as modificações e os impactos nos processos de ensino e aprendizagem no contexto atual de Pandemia da COVID-19. (3) Realizar uma breve análise das ferramentas de incentivo à leitura empregadas na Aula Paraná e apresentar sugestões de metodologias capazes de auxiliar o ensino neste período, maximizando o uso das TDIC no processo de ensino-aprendizagem de leitura.

O atual contexto de crise de saúde pública instalada pela COVID-19 torna ainda mais urgente à necessidade da realização de pesquisas como esta, tendo em vista a necessidade de o professor rever as metodologias e as ferramentas pedagógicas contemplando o uso das TDIC como aliadas nos processos de ensino e 
aprendizagem nas áreas de leitura e de comunicação. Frente ao exposto, justifica-se a realização deste estudo.

Os procedimentos metodológicos utilizados para a organização da presente pesquisa foram baseados em uma pesquisa de revisão bibliográfica da literatura, de abordagem qualitativa e de caráter descritivo.

Os materiais para a composição do artigo foram selecionados com base nas palavras-chave: Ensino de Língua Portuguesa, Tecnologia no Ensino e Aprendizagem, Leitura, as quais permitiram a identificação e a seleção dos artigos científicos nas bases de dados Scielo, Banco de Teses e Dissertações do Portal de Periódicos da Coordenação de Aperfeiçoamento de Pessoal de Nível Superior (CAPES), site de busca - Google Acadêmico, plataforma de compartilhamento de vídeos - Youtube, além de documentos oficiais da educação como, os Parâmetros Curriculares Nacionais para o Ensino Fundamental (PCNs) e a Base Nacional Comum Curricular (BNCC).

O artigo está dividido em três partes: a primeira parte direciona-se a uma sucinta investigação do modo como a leitura é concebida na Base Nacional Comum Curricular, estabelecendo uma relação entre os multiletramentos e as TDIC. A segunda parte trata da contextualização dos novos modelos de ensino e aprendizagem remotos decorrentes dos impactos no contexto atual de Pandemia. Em seguida, na terceira parte é realizada uma breve análise de uma sequência de aulas de leitura para o $09^{\circ}$ ano do ensino fundamental, disponibilizadas na plataforma Youtube - canal Aula Paraná, associada à sugestão de algumas metodologias direcionadas à maximização dos processos de ensino-aprendizagem e o desenvolvimento das habilidades de leitura frente ao trabalho dos multiletramentos.

\section{A leitura na Base Nacional Comum Curricular (BNCC) e as novas formas de transposição de informação e conhecimento}

A Base Nacional Comum Curricular (BNCC) é um documento que reúne normas e diretrizes para a aprendizagem ao longo da vida escolar do educando. Definida de acordo com $\S 1^{\circ}$ do Artigo $1^{\circ}$ da Lei de Diretrizes de Bases da Educação Nacional LDB (Lei n 9.394/1996) e aplicada em todos os níveis e modalidades de ensino, tal documento é utilizado como referência para a elaboração de currículos escolares e busca a promoção da equidade e unificação dos sistemas públicos ou 
privados, em todo o território nacional. Os textos do BNCC servem como base para as noções de desenvolvimento de competências e habilidades de acordo com cada ciclo da formação escolar (BRASIL, 2017).

Com relação ao modo como a leitura é concebida no documento, ao Ensino Fundamental, observa-se:

[...] nos Anos Finais do Ensino Fundamental, os conhecimentos sobre a língua, sobre as demais semioses e sobre a norma-padrão se articulam aos demais eixos em que se organizam os objetivos de aprendizagem e desenvolvimento de Língua Portuguesa. Dessa forma, as abordagens linguística, metalinguística e reflexiva ocorrem sempre a favor da prática de linguagem que está em evidência nos eixos de leitura, escrita ou oralidade (BRASIL, 2017, p.139).

Observa-se que a linguagem deve ser trabalhada na sua íntegra tornando o educando capaz de refletir, realizar e expor o seu conhecimento. O aluno necessita desenvolver habilidades de leitura, escrita e oralidade para que seja capaz de transcorrer também pelas demais disciplinas oferecidas. Além da aprendizagem das normas da língua as quais devem ser elencadas, assim como descrito:

\begin{abstract}
Alguns desses objetivos, sobretudo aqueles que dizem respeito à norma, são transversais a toda a base de Língua Portuguesa. O conhecimento da ortografia, da pontuação, da acentuação, por exemplo, deve estar presente ao longo de toda escolaridade, abordados conforme o ano da escolaridade. Assume-se, na BNCC de Língua Portuguesa, uma perspectiva de progressão de conhecimentos que vai das regularidades às irregularidades e dos usos mais frequentes e simples aos menos habituais e mais complexos (BRASIL, 2017, p.139).
\end{abstract}

Neste contexto os conhecimentos prévios não são desprezados, mas considerados por meio da intercomunicação reconhecida na necessidade de interpretar e fixar os saberes.

A prática da leitura, de acordo com a BNCC, dentro do ensino fundamental, compreende as práticas de linguagem, realizadas a partir da interação ativa criada entre os personagens, sendo: o leitor, o ouvinte, o espectador e os textos, podendo ser estes escritos, orais ou multissemióticos.

Outro fator importante diz respeito aos aspectos trabalhados no ensino da leitura, como: a interpretação, a fruição estética de textos e obras literárias, a pesquisa e o embasamento de trabalhos escolares, o conhecimento, a discussão e o debate acerca dos temas sociais, e a aquisição do conhecimento estendido para projetos sociais e outras possibilidades. O mesmo documento indica que este ensino seja feito de forma progressiva, assim, nas atividades de leitura o professor deve 
intermediar a ampliação dos vocábulos, além de oferecer leituras diferenciadas, proporcionando uma apresentação de novos conteúdos e aprendizagens. Neste âmbito, observa-se uma transformação do aluno que, com a prática da leitura, desenvolve diversas formas de interpretação de mundo e habilidades cognitivas mais complexas (BRASIL, 2017).

Considerando as práticas de leituras sociais pós modernas, em que os leitores são expostos à informações que intercalam a presença de signos escritos, layout e imagens visuais, sons, objetos 3D etc., constituídas pelos diferentes tipos de letramentos: matemáticos, literários, jurídicos, digitais, entre outros, nos últimos anos, diferentes pesquisas têm sido realizadas com o intuito de contribuir com as correntes linguísticas direcionadas à multiculturalidade, característica das sociedades globalizadas, bem como as consequentes multimodalidades de textos representados pelos multiletramentos (ROJO, 2012).

Como forma de promoção dos fundamentos pedagógicos e da integralidade da educação, a BNCC oficializa, reconhece $e$ investe nos conceitos de multiletramentos no ensino da Língua Portuguesa no Brasil, valorizando-os como uma importante forma de abordagem no ensino da área de linguagem, no que diz respeito à preparação do educando para os desafios encontrados nos diversos espaços ocupados por ele, seja na vida social, profissional, bem como no exercício da cidadania, dando, assim, uma nova amplitude para a utilização das novas TDIC, corroborando para ideias de inclusão e democracia defendidos pelo documento (BRASIL, 2017).

Conforme (BARBOSA, 2004), o termo dos multiletramentos foi desenvolvido na década de 1990 por um grupo de pesquisadores da Austrália, denominado New Group, com o intuito de ampliar as abordagens tradicionais acerca dos letramentos que focavam os estudos, unicamente em textos escritos, formas de linguagem formais, monolíngues e monoculturais, baseadas em regras gramaticais, como correlação entre letra e som. A intenção deste novo conceito é promover uma reflexão crítica acerca dos diferentes aspectos socioculturais, formas e práticas de letramento que surgem em meio às culturas heterogêneas, periféricas e digitais, proporcionando a conscientização, a inclusão e a valorização de todos os tipos de cidadãos.

A definição de multiletramentos envolve uma multiplicidade de culturas e linguagens provenientes destes contextos sociais contemporâneos, incluindo as 
digitais, os quais refletem a multiplicidade semiótica de constituição dos textos. Sobre o aspecto da associação com as TDIC, apontam que:

[...] Diferentemente das mídias digitais anteriores (impressas e analógicas como a fotografia, o cinema, o rádio e a TV pré-digirais), a mídia digital, por sua própria natureza "tradutora" de outras linguagens para a linguagem dos dígitos binários e por sua concepção fundante em rede (web), permite que o usuário (ou o leitor/produtor de textos humano) interaja em vários níveis e com vários interlocutores (interface, ferramentas, outros usuários, textos/discursos etc. (ROJO e MOURA 2012, p. 23)

Em sala de aula o trabalho com os multiletramentos pode ser voltado ao desenvolvimento de atividades de ensino e de aprendizagem com o intuito de promover a leitura e a escrita frente às diferentes práticas sociais das linguagens. Neste formato de ensino, a atribuição dos sentidos e mensagens são adquiridas a partir de textos, fotos, desenhos, ilustrações, livros didáticos, leituras de cordel, propagandas, revistas e, em especial, pelos veículos virtuais, digitais, audiovisuais e multimodais que permeiam a diversidade cultural, na qual as TDIC se inserem, tornando o ensino mais interativo, colaborativo, híbrido em linguagens, mídias e culturas (BARBOSA, 2004).

A BNCC (2017) complementa que os multiletramentos transpassam as aulas de Língua Portuguesa, uma vez que têm a possibilidade de integrar, em um único ensino, diferentes conteúdos e disciplinas, interligando os assuntos e tornando-os multidisciplinares. O mesmo documento elenca que a linguagem deve ser trabalhada plenamente, tornando o educando capaz de refletir, realizar e expor o conhecimento de forma prática, efetiva, crítica e reflexiva a partir da utilização dos novos mecanismos digitais, como é o caso das TDIC.

Deste modo, BARBOSA (2004) apresenta os multiletramentos como uma nova proposta de "pedagogia de alfabetização" com o foco direcionado sobre os eixos da comunicação e das variâncias dos significados existentes nos diferentes cenários da vida cotidiana, em consonância com as multimodalidades provenientes dos novos meios tecnológicos de informação e comunicação, tendo em vista que a alfabetização focada nas regras gramaticais tornou-se insuficiente, demonstrando a necessidade de preparar o aluno para aptidões que possam proporcionar o contato e o conhecimento de múltiplos ambientes sociais pelos quais a comunicação transcorre.

Essas diferenças são influenciadas por fatores culturais, classe social, gênero, experiência de vida, campo de trabalho, disciplinas exploradas no ambiente 
acadêmico. Assim, os multiletramentos proporcionam uma alfabetização exploratória onde se transita pelas diversas formas de expressão da língua (BARBOSA, 2004).

Nos últimos tempos, a BNCC (2017) passou a mostrar-se mais flexível quanto à liberação do uso das TDIC em sala de aula, reconhecendo tais ferramentas como importantes no processo de ensino aprendizagem, um direito de aprendizagem nas competências a nível infantil, fundamental e médio. Segundo o documento, a diversificação de linguagens, incluindo a digital deve ser utilizada no ensino com o intuito de expressar e partilhar informações, expressões, experiências e sentimentos nos mais variados contextos, favorecendo, assim, a compreensão mútua. Para isso, é importante que as tecnologias digitais de informação sejam criadas, compreendidas e utilizadas de forma crítica, significativa, reflexiva e ética, inserida nos diferentes contextos e práticas sociais de disseminação da comunicação e informação. Tomando como base as considerações expostas pela BNCC, acredita-se, de acordo com (VIEGAS, 2020), que o uso de softwares, plataformas e TDIC de um modo geral, contribuam de forma lúdica, para a motivação, o interesse e o aprendizado de alunos que se encontram em formato de ensino remoto ou híbrido.

\section{Ensino e aprendizagem em tempos de Pandemia}

Os efeitos provocados pela Pandemia COVID-19 (SARS-CoV-2) no ano de 2020, em virtude da necessidade de ficarmos em casa para proteger-nos como medida fundamental para o enfrentamento da doença e a redução de seus avanços, impactaram de forma negativa diferentes setores sociais e de atividades humanas em todo o mundo, incluindo o campo da educação, uma vez que paralisou as atividades realizadas em unidades escolares, creches, pré-escolas, escolas preparatórias, técnicas, universidades, etc. (SENHORAS, 2020).

As tecnologias, de modo geral, conforme (ANTUNES NETO, 2020), nunca foram tão necessárias e utilizadas como no presente momento. O novo cenário de ensino modificou a rotina dos alunos e, principalmente dos educadores em decorrência dos novos desafios e a necessidade de modificação e/ou aprimoramento de metodologias de ensino alternativas inovadoras até então não utilizadas por muitos educadores no ambiente natural de sala de aula onde lecionam (MARQUES, 2020). 
Assim, o ensino remoto promovido pelo uso das tecnologias digitais on-line apoiadas pelas TDIC, que antes tratava-se de uma prática mais comumente observada no cenário de Ensino a Distância (EAD) em nível superior, considerado uma ferramenta opcional e adicional às aulas em formatos presenciais, como citam FORMOSINHO; MACHADO e MESQUITA (2015), na situação atual, tornou-se uma alternativa educacional de adaptação à nova realidade para que os alunos das demandas dos ensinos infantil, fundamental e médio pudessem ser atendidos de forma ativa com continuidade no processo de ensino e aprendizagem e minimização dos prejuízos decorrentes da suspensão do ano letivo desde Março de 2020.

Para os professores que já se apropriavam destes recursos em sala de aula a introdução dos novos formatos de docência foram mais fáceis, em contrapartida, aqueles que não possuíam familiaridade com as ferramentas tecnológicas se viram diante de um novo desafio: o de aprender como utilizar os novos recursos, a fim de oferecer um ensino com o mesmo (ou semelhante) padrão presencial aos educandos, proporcionando a todos um ensino igualitário e de qualidade.

Deste modo, conforme (MARQUES, 2020), os professores e toda a equipe gestora tiveram que repensar acerca das práticas de ensino até então utilizadas, e modificar as metodologias e práticas pedagógicas em uma velocidade compatível às necessidades emergenciais exigidas pela Pandemia.

O mesmo cenário de necessárias e emergentes modificações educacionais atingiu os alunos quanto às novas formas de desenvolvimento do aprendizado. De acordo com (ANTUNES NETO, 2020), os educandos se depararam com uma situação inusitada tendo que assumir a responsabilidade de protagonismo e autonomia frente ao próprio processo de estudo, em decorrência da ausência de tutor diário e presencial para o auxílio na execução das tarefas.

Tais modificações resultam na possibilidade de construção de novos hábitos e liberdade de aprendizagem.

Outra questão tão importante quanto o uso das tecnologias por parte dos professores, diz respeito ao acesso dos alunos a estes veículos tecnológicos, uma vez que o Brasil é marcado por uma desigualdade social econômica a qual distancia boa parte dos alunos do contato com instrumentos necessários para o ensino e aprendizagem remotos, como televisão, celular e computador. Verifica-se que mesmo aqueles que possuem equipamentos adequados para as aulas, nem sempre têm a acessibilidade ao sinal de internet necessário (BURGESS et al., 2020). Este 
fato é confirmado pelos dados disponibilizados por uma pesquisa realizada pelo Instituto Brasileiro de Geografia - IBGE (2019), o qual aponta que cerca de 46 milhões de brasileiros não possuem acesso à internet.

Antunes Neto (2020) e Burgess et al. (2020) apontam que paralelamente aos esforços dos professores e dos alunos, e não menos importante, destacam-se a dedicação das famílias que também se empenham e se sobrecarregam a fim de monitorar as presenças e acompanhar as atividades de modo a auxiliar o processo de promoção da educação domiciliar de forma efetiva ao aprendizado das crianças e adolescentes.

\section{Análise das práticas pedagógicas de incentivo à leitura no cenário de ensino remoto na Pandemia do COVID-19 no Estado Paraná}

Como forma de estratégia de enfrentamento à Pandemia, a Secretaria Estadual da Educação e do Esporte - SEED (2020) do Estado do Paraná, criou o Aula Paraná, atendendo a Coalizão Global de Educação lançada pela Unesco para dar a crianças e jovens acesso a várias opções de aprendizado inclusivo durante o período dessa interrupção súbita e sem precedentes na educação. O Aula Paraná é um sistema de aulas não presenciais que engloba cinco ferramentas que representam estratégias adotadas para garantir a continuidade das aulas:

[...] as estratégias são a transmissão de videoaulas na tv aberta, o uso dos aplicativos aula Paraná e google classroom, disponibilização do conteúdo também no youtube e a entrega de material impresso (agência de notícias do paraná, 2020).

Com a adoção dessas estratégias, o educando assiste às aulas disponibilizadas, tem a possibilidade de rever as aulas apresentadas e os slides com os conteúdos exibidos pelos professores, realiza as atividades e avaliações propostas, posta as tarefas sugeridas e interage com o professor para tirar dúvidas, tendo possibilidade de fazê-lo tanto de forma conjunta no mural do Google Classroom e grupos de WhatsApp ou de modo privado, e dar ciência da sua presença respondendo a chamada no link. Há, ainda, o Google Meet, uma sala virtual em que alunos e professor podem interagir em tempo real. É importante destacar que, na impossibilidade de acesso, todos os materiais e conteúdos trabalhados são distribuídos de forma impressa, garantindo que todos os alunos sejam atendidos (SEED, 2020). 
O ensino remoto por meio do Aula Paraná tem se apropriado de recursos tecnológicos que possibilitam aos professores a exploração de novos meios de comunicação. As aulas três ${ }^{2}(43 \mathrm{~m} 42 \mathrm{~s})$ e quatro ${ }^{3}(43 \mathrm{~m})$, voltadas ao $09^{\circ}$ ano do Ensino Fundamental II disponibilizadas na Plataforma Aula Paraná - Youtube, no dia 13 de abril de 2020, e aula cinco ${ }^{4}$ (54m39s) voltada à mesma turma e exibida no Canal, no dia 14 de Abril de 2020, tiveram como objetivo proporcionar aos alunos o ensino e o desenvolvimento da habilidade de leitura, interpretação e compreensão de textos por meio do uso do gênero textual literário: contos. As videoaulas analisadas estão descritas a seguir.

A aula três e a aula quatro, continuação do conteúdo anterior, foram utilizadas para a apresentação e a análise do conto "O diabo e outras histórias", na aula cinco o conto trabalhado foi: "O grande tigre de bengala". As aulas três e cinco foram iniciadas com uma breve discussão acerca do gênero textual conto a partir de questionamentos específicos, como: o que é? Quais as características? Quais os tipos? Qual a aproximação com outros textos e contextos? etc., a fim de promover o interesse e a motivação à leitura do texto. Em seguida, a professora lançou aos alunos a proposta e a leitura apresentação do conto, orientando-os a acompanhá-la em tempo real por meio do apoio do material escrito disponibilizado no livro didático. É importante destacar a presença dos recursos de voz utilizados pela professora com o intuito de atrair a atenção dos alunos, sendo, a entonação, modulação vocal, o ritmo e a prosódia aplicados durante a leitura. Após, foi realizada uma breve apresentação acerca da biografia do autor, de modo que os educandos compreendessem o contexto histórico no qual os textos encontravam-se inseridos quando escritos, as escolas literárias pertencentes, entre outros aspectos. Os passos seguintes trataram da explanação de perguntas interpretativas acerca do texto utilizando-se de estratégias de retomada de trechos, a fim de identificar as relações estabelecidas entre os personagens, o narrador, o tempo, os aspectos gramaticais e a ideia central do texto, buscando o desenvolvimento completo das habilidades leitoras. Ao final de cada aula foram disponibilizadas atividades avaliativas por meio de quiz a fim de identificar o aprendizado dos alunos frente aos

\footnotetext{
2 Disponivel em: https://www.youtube.com/watch?v=CN3GM3AilyQ\&list=PLnGI1S4A8ru5yesAVeiEOnI5ZvY9SxEc\&index=3. Acesso em: 06 set. 2020.

3 Disponível em: https://www.youtube.com/watch?v=xREb1tsUkFc\&list=PLnGI1S4A8ru5yesAVeiEOnl5ZvY9SxEc\&index=4. Acesso em: 06 set. 2020.

$4 \quad$ Disponível em: https://www.youtube.com/watch?v=NNeY9JztQPI\&list=PLnGI1S4A8ru5yesAVeiEOnI5ZvY9SxEc\&index=5. Acesso em: 06 set. 2020.
} 
conteúdos apresentados.

Por meio da análise realizada quanto à apresentação das propostas sugeridas para trabalhar os contos, observa-se que, embora trate-se de uma exposição sem a presença física dos alunos, em decorrência do ensino remoto, todas as aulas foram realizadas com a utilização de uma sequência didática planejada e organizada em seguimento às orientações apresentadas pelo livro didático e com base em uma postura construída por uma perspectiva interacionista e discursiva da linguagem (CEREJA, 2004). Autores como Cereja (2004), indicam sobre o uso da perspectiva dialógica interacionista de ensino da leitura, com a justificativa de que a prática leitora é constituída de um hábito adquirido a partir de um contato complexo e gradual com os diferentes textos que, por sua vez, capacitam os alunos a um aprendizado crítico e reflexivo das leituras.

A apropriação desta teoria é verificada no momento em que a professora fornece espaços contextualizadores e dinâmicos marcados por pausas utilizadas para trocas e reflexões (ainda que virtuais), de modo a aproximar os alunos dos cenários e dos conteúdos literários, corroborando com o interesse, a motivação, a compreensão dos materiais estudados e a consequente formação de leitores autônomos intelectualmente, críticos e questionadores. De acordo com Strogenski e Soares (2011), a contextualização da temática e do gênero literário quando realizada por meio de uma discussão, trocas de vivências, experiências, conhecimentos, leva os alunos a construção de percepções quanto aos aspectos sociais, culturais, políticos e econômicos atuais e da época estudada, favorecendo a interpretação, compreensão, análise crítica textual e correlação com os aspectos contemporâneos.

Verifica-se, então, o esforço da professora em promover trocas ainda que por meio de compartilhamento de experiências, tendo em vista a ausência de possibilidade de diálogo entre os alunos, promovendo, assim, o incentivo às diferentes formas de leitura, nesta aula representada pelo conto e favorecendo o desenvolvimento das habilidades de leitura.

Antunes Neto (2020) aponta que no período atual de ensino remoto no qual a sociedade encontra-se inserida, uma importante parte do sucesso das aulas e da aprendizagem dos alunos depende do domínio tecnológico do professor, do uso das interfaces operacionais, aplicativos, plataformas, entre outros recursos. As tecnologias são utilizadas como uma ferramenta dependente da tutela dos educadores e exige habilidades diferenciadas das estabelecidas em tempos e 
espaços socioculturais anteriormente estabelecidos. A experiência interativa das aulas, ainda que simples e objetiva devem ser sustentadas pelas tecnologias sendo capazes de atrair e manter a atenção dos alunos durante as aulas. Segundo o autor, o progresso tecnológico aqui alcançado será, provavelmente irreversível e estendido também ao período pós pandemia, por isso a necessidade de aperfeiçoamento.

Entretanto, o uso das tecnologias de forma isolada não é suficiente. É fundamental que estas ferramentas não sejam engessadas pelos conteúdos e as técnicas transformando o ensino remoto em uma extensão das aulas tradicionais, por outro lado, visa-se a necessidade da utilização tecnológica de forma crítica, a fim de transformar os novos espaços em cenários próprios permeados pelo conhecimento, a criatividade e a interdisciplinaridade. Para isso, deve-se levar em consideração a inserção destas metodologias no planejamento pedagógico de mediação, a partir de aspectos específicos dos sujeitos envolvidos, como: a faixa etária educacional, a realidade social, cultural, econômica etc. (SANTOS, 2010; GOEDERT; ARNDT, 2020).

Um recente estudo realizado por Médici; Tatto e Leão (2020) investigou a percepção de 105 alunos matriculados no ensino médio de uma rede de educação pública quanto a experiência nas aulas remotas no período de Pandemia. Dos entrevistados, $29,9 \%$ classificaram o ensino como excelente ou bom, 38,6\% como regular e os demais $31,7 \%$ como ruim ou péssimo. Ao serem questionados se estão aprendendo da forma como deveriam 95\% respondeu que não ou em partes, dentre os respondentes, $16 \%$ disseram que o ensino apresenta deficiências quanto à estrutura e metodologias e $07 \%$ queixaram-se quanto à necessidade de evolução na implantação de tecnologias.

Em relação a este assunto, verifica-se que apesar da qualidade dos conteúdos, da organização e da abordagem observadas nas aulas de contos expostas no canal Aula Paraná, o modo de lecionar apresentado nas videoaulas ainda é baseado em um formato expositivo com inserção tímida das diferentes possibilidades e recursos disponíveis para o uso das TDIC em sala de aula, virtual ou presencial. É natural que isso aconteça, tendo em vista a velocidade com que os professores precisaram se readaptar ao "novo normal" e aprender como utilizar e aplicar ferramentas tecnológicas, oferecendo uma aprendizagem de qualidade, bem como a ausência de políticas e legislações que regulamentem o Ensino a Distância nesta faixa de ensino. 
Com relação aos instrumentos utilizados, além do livro didático, a educadora apropriou-se do uso de materiais como: lousa, imagens, ferramentas digitais e TDIC como: notebook, recursos de apresentação dos slides e o vídeo-aula propriamente dito. As ferramentas utilizadas proporcionaram o acompanhamento dos textos e a execução das tarefas de forma fácil e didática. Frente a mudanças rápidas como as visualizadas, surgem diferentes prerrogativas: Quais outras ferramentas tecnológicas podem auxiliar os educadores no contexto atual de aulas remotas? Como os professores podem otimizar e maximizar o ensino e a aprendizagem da leitura a partir de estratégias digitais de multiletramentos?

Goedert e Arndt (2020) apontam que, antes de se pensar em respostas a estes questionamentos, é fundamental lembrar que o formato de educação disponibilizado atualmente pela educação básica não se trata de um ensino EaD, mas, um modelo que se apropria de metodologias desta modalidade. Embora o ensino totalmente híbrido ou remoto em virtude do distanciamento social trate-se de um assunto recente, o uso de metodologias e tecnologias para a educação a distância tem sido uma temática bastante discutida pela literatura ao longo dos últimos anos.

Um estudo realizado por Moreira et al. (2020) investigou as propostas de educação, ensino-aprendizado e metodologias ativas utilizadas em todo o país para a educação em tempos de Pandemia provocada pela COVID-19.

Após o levantamento, os autores identificaram a utilização de aulas síncronas semelhantes às aulas a distância por meio das ferramentas Youtube, Google Classroom, Google Meet, Plataforma Zoom (com participação por meio de áudio, vídeo e chat), a disponibilização da ferramenta Plurall, redes sociais comunicadoras (WhatsApp), redes de relação interpessoal (Facebook), e utilização de ambientes virtuais - AVA como o Moodle, as quais permitem a partilha de e-books e textos em formatos PDF com o intuito de incentivar a leitura, a última citada possibilita ainda, a disponibilização de diferentes tipos de atividades e avaliações do desempenho dos alunos. Além das metodologias mais utilizadas, os autores destacam, ainda, a existência de importantes e atrativas plataformas lúdicas que baseiam o ensino e o aprimoramento da leitura por meio de jogos e gamificações, são elas a Kahoot e a Kademi.

Na mesma perspectiva Silva e Leite Filho (2020) destacam a existência de um software voltado ao auxílio do ensino da leitura e da Língua Portuguesa no 
período de Pandemia e atividades remotas. O software "Luz do Saber" é uma ferramenta de ensino totalmente on-line e gratuita, disponibilizada pela Universidade Federal do Ceará. Além desta, outras ferramentas de outras disciplinas também se encontram disponíveis, como: o software Células Virtuais, voltado ao ensino de Biologia; o Ludo Químico, direcionado à disciplina de Química; o Efeito Fotoelétrico, relacionado ao ensino e aprendizagem de Física; e o Laboratório Virtual de Matemática.

Outro software disponível para o estímulo da Literatura é o HagáQuê elaborado por Viana et al. (2019), uma plataforma gratuita voltada à promoção do desenvolvimento da leitura, interpretação textual, criatividade, escrita e inclusão digital a partir da criação de histórias em quadrinhos. Vale destacar também a existência de um site denominado Racha Cuca, indicado pela Secretaria Estadual de Educação do Estado de São Paulo. Este site possui incentivos à leitura por meio da aplicação de jogos como caça palavras e jogo da forca (LANDIN, 2015).

Além das ferramentas listadas os Podcasts e os audiobooks também se destacam como importantes estratégias metodológicas digitais multimodais voltadas ao trabalho com a Língua Portuguesa. Tais ferramentas fornecem aos alunos a leitura de uma forma mais instigante uma vez que disponibilizam conteúdos de leitura/auditiva que possibilitam o aprendizado de histórias de literatura, contos, poemas, narrativas entre outros gêneros literários.

A continuidade das atividades educacionais de forma remota, apoiadas nas TDIC impactam diretamente na redução da evasão escolar e na manutenção do envolvimento e comprometimento dos alunos, tanto para o período atual de Pandemia, quanto para o período posterior de retomada das atividades presenciais, assim, enfatiza-se a necessidade de estudo, investimento e planejamento para o uso adequado e consciente das metodologias e ferramentas digitais, favorecendo um ensino de qualidade (SENHORAS, 2020).

\section{Considerações finais}

O contexto de manter distância de outras pessoas, para cuidado e prevenção acarretou importantes desafios e mudanças para a educação, paralelamente, intensificou outros questionamentos pré-existentes, como a inserção das tecnologias junto ao planejamento e currículos tradicionais. Neste sentido, 
diferentes e importantes debates têm sido realizados em torno do uso das TDIC no cenário do ensino em formato remoto.

O uso das metodologias é fundamental para que os alunos tenham acesso ao ensino em um período em que se encontram impedidos de frequentar as escolas de maneira presencial.

Entretanto, vale relembrar que os educadores continuam sendo um elemento fundamental de exploração do potencial pedagógico destas tecnologias e mediação do ensino, no que diz respeito ao planejamento, condução, transmissão de conhecimentos e propagação do processo educativo, mesmo frente a tantas ferramentas e estratégias atrativas e motivadoras.

A análise realizada em algumas das aulas disponíveis no sistema Aula Paraná evidenciou a inserção e o uso de tecnologias para o ensino da literatura. Por outro lado, destacou aspectos passíveis de serem aprimorados, favorecendo uma maior e mais efetiva aprendizagem na área da Língua Portuguesa. Com o intuito de auxiliar a maximização do ensino por meio do planejamento de educadores, buscouse deixar destacado neste estudo, algumas das ferramentas e metodologias disponíveis na literatura direcionadas ao ensino remoto, principalmente no período de Pandemia provocada pela COVID-19 na qual o país encontra-se atualmente.

Sendo assim, espera-se que este artigo auxilie os professores na inserção destes espaços com qualidade, motivando-os ao uso das práticas de ensino e incentivo da leitura com o auxílio de metodologias que contemplem a diversidade de gêneros e tipos textuais que compõem a Língua Portuguesa, a partir do uso das TDIC.

\section{Referências}

AGÊNCIA DE NOTÍCIAS DO PARANÁ. Ensino a distância cobre 99,7\% do Estado. 2020. Disponível em: <http://www.aen.pr.gov.br/modules/noticias/article.php?storyid=107089>. Acesso em: 06 set. 2020.

ANTUNES NETO, J.M.F. Sobre ensino, aprendizagem e a sociedade da tecnologia: por que se refletir em tempo de pandemia? Revista Prospectus, v. 02, n. 01, p. 2838, ago. /fev., 2020.

AULA PARANÁ. $09^{\circ}$ Ano Língua Portuguesa Aula 03 - Conto: O diabo e outras histórias. 2020. (45m51s). Disponível em:

<https://www.youtube.com/watch?v=CN3GM3AilyQ\&list=PLnGI1S4A8ru5yesAVeiEOnI5ZvY9SxEc\&index=3>. Acesso em: 19 ago. 2020. 
AULA PARANÁ. $09^{\circ}$ Ano Língua Portuguesa Aula 04 - Conto: O diabo e outras histórias. 2020. (42m59s). Disponível em:

$<$ https://www.youtube.com/watch?v=xREb1tsUkFc\&list=PLnGI1S4-

A8ru5yesAVeiEOnl5ZvY9SxEc\&index=4>. Acesso em: 19 ago. 2020.

AULA PARANÁ. $09^{\circ}$ Ano Língua Portuguesa Aula 05 - Conto: O grande tigre de bengala. 2020. (54m38s). Disponível em:

<https://www.youtube.com/watch?v=NNeY9JztQPI\&list=PLnGI1S4-

A8ru5yesAVeiEOnI5ZvY9SxEc\&index=5>. Acesso em: 19 ago. 2020.

BARBOSA, E.D. Letramentos e multiletramentos: um estudo etnográfico com professores em uma escola pública estadual na cidade de Itabuna. 2014,108p. (Dissertação) Mestrado em Letras: linguagens e representações - Universidade Estadual de Santa Cruz, Ilhéus - BA, 2014.

BRASIL. Ministério da Educação. Leis de Diretrizes e Bases da Educação nacional. Lei $n^{\circ}$ 9.394/96 de 20 de dezembro de 1996. 1996. Disponível em:

<http://www.planalto.gov.br/ccivil_03/leis//9394.html>. Acesso em: 17 ago. 2020.

BRASIL. Ministério da Educação. Secretaria de Educação Básica Parâmetros Curriculares Nacionais. Secretaria de Educação Básica - Brasília. DF. 1997

Disponível em: <chrome-

extension://oemmndcbldboiebfnladdacbdfmadadm/http://portal.mec.gov.br/seb/arquiv os/pdf/livro0>. Acesso em 17 ago. 2020.

BRASIL. Ministério da Educação. Base Nacional Comum Curricular. 2017.

Disponível em: <chrome-

extension://oemmndcbldboiebfnladdacbdfmadadm/http://basenacionalcomum.mec.g ov.br/images/BNCC_EI_EF_110518_versaofinal_site.pdf>. Acesso em: 18 ago. 2020.

BURGESS, S.; SIEVERTSEN, H. H. "Schools, skills, and learning: The impact of COVID-19on education”. VOX CEPR Policy Portal. 2020. Disponível em:

<https://voxeu.org/article/impactCOVID-19-education>. Acesso em: 19 ago. 2020.

CEREJA, W.R. Ensino de Literatura: uma proposta dialógica para o trabalho com literatura. São Paulo: Atual, 2005.

CRUZ, J.M.O. Processo de ensino-aprendizagem na sociedade da informação. Educ. Soc., Campinas, v. 29, n. 105, p. 1023 -1042, set./dez. 2008.

FORMOSINHO, J.; MACHADO, J.; MESQUITA, E. Formação, trabalho e aprendizagem. Tradição e inovação nas práticas docentes. Lisboa: Edições Sílabo, 2015.

GOEDERT, L.; ARNDT, K.B.F. Mediação pedagógica e educação mediada por tecnologias digitais em tempos de pandemia. Criar Educação, Criciúma, v. 09, n. 02, Edição Especial 2020.

INSTITUTO BRASILEITO DE GEOGRAFIA E ESTATÍSTICA - IBGE. Pesquisa Nacional por Amostra de Domicílios Contínua PNAD Contínua Mercado de Trabalho 
Brasileiro. 2019. Disponível em:

<https://www.ibge.gov.br/estatisticas/sociais/trabalho/17270-pnad-continua.html.> Acesso em: 19 ago. 2020.

LANDIN, R.C.S. Softwares educativos no contexto da alfabetização e do letramento nos anos iniciais do Ensino Fundamental. 2015. 169p. (Dissertação) Mestrado em Educação - Universidade Federal de São Carlos, São Carlos - SP. 2015.

LÉVY, P. Cibercultura. São Paulo: Editora 34, 1999.

MARQUES, R. A ressignificação da educação e o processo de ensino e aprendizagem no contexto de pandemia da COVID-19. Revista UFRR, ano II, v. 03, n.07, Boa Vista, 2020.

MÉDICI, M.S.; TATTO, E.R.; LEÃO, M.F. Percepções de estudantes do Ensino Médio das redes pública e privada sobre atividades remotas ofertadas em tempos de pandemia do Corona vírus. Revista Thema, v.18, especial, 2020.

MOREIRA, M.E.S. et al. Metodologias e tecnologias para educação em tempos de pandemia COVID-19. Braz. J. Hea. Rev., Curitiba, v. 03, n. 03, p.6281-6290. 2020.

PINHEIRO, N.A.M., et al. Refletindo acerca da ciência, tecnologia e sociedade: enfocando o ensino médio. Revista Iberoamericana de Educación, n.44, maioagosto, 2007.

ROJO, R.; MOURA, E. Multiletramentos na escola. São Paulo: Parábola Editorial, 2012.

SANTOS, M. et al. Ensinar e aprender com a metodologia Syllabus. Revista de Educação, Brasília, n. 150, ano 38, jan./jun. 2010.

SECRETARIA ESTADUAL DA EDUCAÇÃO E DO ESPORTE - SEED. AULA PARANÁ. 2020. Disponível em: <http://www.aulaparana.pr.gov.br/>. Acesso em: 19 ago. 2020.

SILVA, J.P.B.; LEITE FILHO, D.M. Softwares educacionais e suas aplicações em tempos de pandemia: estudo sobre possibilidades de aplicação. J. of Develop., Curitiba, v. 06, n. 07, jul. 2020.

SENHORAS, M. Coronavírus e educação: análise dos impactos assimétricos. Revista UFRR, ano II, v. 02, n. 05, Boa Vista, 2020.

STROGENSKI, M.J.F.; SOARES, S. Ensino de Literatura: uma proposta por unidade temática. Revista Ao pé da Letra, v.13, n.02, 2011.

VÁSQUEZ, A. S. Filosofia da Práxis. Rio de Janeiro: Paz e Terra, 1968.

VIANA, F.B., et al. Hagá Quê: software educativo auxiliando na produção textual com turmas do ensino médio na disciplina de Língua Portuguesa. In: ANAIS DA SEMANA DE INFORMÁTICA, CESIT/UEA, v.07, n.02, Manaus, 2019. 
VIEGAS, A. Como o uso da tecnologia é previsto pela Base Nacional Comum Curricular (BNCC)? 2020. Disponível em: <https://www.somospar.com.br/como-ouso-da-tecnologia-e-previsto-pela-base-nacional-comum-curricular-bncc/>. Acesso em: 02 jul. 2020. 